\title{
The use of information systems in the Greek public financial services: the case of TAXIS
}

\author{
Marianthi H. Terpsiadou \& Anastasios A. Economides \\ Information Systems Department, University of Macedonia, \\ Egnatia 156, Thessaloniki 54006, Greece
}

\begin{abstract}
One of the most important transactions between government and citizens is the taxation. The modernisation efforts of the public sector using information and communication technology (ICT) have led to the application of large information systems. TAXIS (TAX Information System) is a major information system in the Greek public financial sector. It supports the Inland Revenue Services' employees to serve the citizens and the state. This study investigated the TAXIS usage and its evaluation by the tax office employees. An appropriate questionnaire was developed and distributed to tax office employees in three branches. The analysis of one hundred responses revealed useful results for governmental policy makers, tax officials as well as public information system developers. Most responders were pleased with TAXIS characteristics except of the handbooks' effectiveness and the system's speed. Gender differences were located in their daily usage, problems' awareness, feelings and considerations about the security of TAXIS.
\end{abstract}

Keywords: E-Government; Electronic Tax Filling; E-Taxation; Evaluation; Government Information Systems; Inland Revenue Services; Online Tax Filling; Public Financial Services; Public Information Systems; TAXIS; Tax Office Employees.

\section{Introduction}

Today, governments all around the world have been profited by the use of Information Technology (IT) in many ways. Taking into consideration the investment in technology and the possibility for functional costs' reduction, it is 
critical the acceptance of electronic-governmental services from both the citizens' and the public employees' point of view.

In Greece, the Operational Programme Information Society (www.infosoc.gr) promotes the Information and Communication Technology (ICT) in the public sector. Electronic Government (E-government) is the transformation of the public sector organisation using ICT in order to serve better the citizen and the enterprises. Electronic governing does not concern only about supplying on-line services, but recommends new technological processes that promote the interaction between citizens and government (Gouscos et al., 2000). The taxation of individual and legal persons is the "tool" that a State Government uses in order to assemble revenues and support the governmental work. However, for the successful operation of a tax authority as well as of a Government, it is essential the proper use of the public financial services information systems by the tax employees (Beattie and Pratt, 2003).

The present study focuses on the Greek tax office employees. Specifically, this study examines the use of the Greek tax information system (TAXIS) by the revenuers and tax office employees. A survey was developed in order to investigate the use of the TAXIS and the users' attitudes towards it. The findings could be useful to government policy and decision makers, government agencies, and public information system developers in a tax authority environment. Although, there are several studies regarding e-taxation and the use of electronic tax web pages by tax payers (Economides and Terzis, 2008), there were not any previous studies on the use of such public financial information systems by tax officials. So, this study investigates the TAXIS use by tax office employees.

\section{Previous studies}

Although IT has been adopted by many public authorities worldwide, the underdeveloped countries remain behind and fail in the import and use of new technologies (Norris, (2001). The use of ICT offers a new frame for the rearrangement of relations between the citizens and the state. Although e-taxation is a promising e-government service, it requires continuous effort for development (Rocheleau and $\mathrm{Wu}, 2005)$. 
Many studies (Hirschheim and Smithson, 1999; Jones et al., 2007; Irani, 2002; Irani and Love, 2001; Remenyi et al., 2000; Willcocks and Lester, 1999) pointed out that most public sector organisations did not support the efficient and effective deployment of new technology. Irani and Love (2001) pointed out the significance of human and organisational factors. Remenyi et al. (2000) argued that without frequent evaluation it is nearly certain that the information system will not meet the changing needs of the organisation. It is important that the senior management participates in the design, development and use of the system. Willcocks and Lester (1999) focused on measures such as Return on Investment, Return on Management, Cost savings, Sales growth and System availability. Jones et al. (2007) illustrated that senior executives need to actively engage with the e-government agenda and provide adequate stewardship, sponsorship, clarity of responsibility and resources. Altameem et al. (2006) stated that using e-Government, the state and the public sector could gain many profits such as reducing time and cost, as well as increasing the efficiency and the effectiveness of public services.

Regarding the e-taxation services, Wang et al. (2005) argued that computer self efficacy affects the users' behavioural intention to use a website. Ease of use, usefulness and credibility are all important factors. Sharma and Yurcik (2004) showed that the tax payers' tendency to use tax filing websites depends on the easiness of use and safety. Moon and Welch (2005) investigated the attitude of citizens and public employees towards the effectiveness of electronic governing. They showed that civil servants are more familiarized, better informed and more certain for the prospect of governing than the citizens. Furthermore, citizens are worried about the safety and the privacy of online tax filling and e-governing. Perceived ease of use, compatibility and trustworthiness are significant predictors of citizens' intention to use an e-government service (Carter and Bélanger, 2005). Terzis and Economides (2007) as well Economides and Terzis (2008) highlighted critical factors that make a tax website successful. They developed an integrated evaluation framework across 5 quality dimensions. Then they used it to evaluate the tax websites of 5 countries.

Public sector should pay attention on both adopting ICT and training the public employees. For example, advanced data mining techniques and knowledge management tools could be used by Inland Revenues (Lau and Halkyard, 2003). The educational level of public employees and their continuing training are important 
factors for the successful implementation of information systems in the public sector. Tax office employees should acquire the needed knowledge in order to deal with the requirements of new advanced technology. Since the nature of doing things will change, governments should invest on people and on continuous training and qualification. For example, the lack of high educational level in combination with socio-economic factors in Syria impeded the investment in ICT (Khoja, 2004).

For many Canadians, their first experience with the electronic governing was the Netfile, an electronic tax filling system through the internet. Millions of Canadians filled their tax forms electronically with great success and without concern about the safety. Bray (2003) argued that the key for a successful electronic tax system is the confidence and trust between state and citizens. The success of the Canadian etaxation system shows that the right IT implementation is not only feasible, but it can also improve the operations of taxation (Malazdrewicz, 1992).

Taylor (2003) suggested the Federal and State tax systems in the United States as examples of successful e-Government. Tax payers can communicate with officials via email and phone, and electronically fill their tax obligation forms. Furthermore, using the bar code technology in the tax returns, the tax payers can scan the electronic data automatically in their computer without the need to import the data by hand (Walsh and White, 2000). However, citizens in Taiwan were not willing to use such new systems (Wand, 2003).

\section{TAXIS overview}

Starting on the 1990, Greece developed a strategy to facilitate the availability of the public sector information and services to citizens and public employees (Avgerou, 2002). In this frame, many efforts were made regarding the automation and the redesign of public services using ICT. The main project of the Ministry of Finance was the TAXIS (TAX Information System) (Bronchi, 2001). TAXIS aims at the operation and service improvement of the Ministry of Finance, the proper service of the citizens and the elimination of tax evasion. TAXIS was considered as a model for all the future applications in the Greek public sector (Gouscos et al., 2001). Its planning and implementation initiated during 1993. A committee of public officials, individual experts and private companies evaluated the process of tax collection. It was concluded that the Ministry's operations were to a large extent decentralised causing 
difficult supervision and control (Tsiavos et al., 2002). So, an integrated centralized IS should be developed. Nevertheless, the idea of centralized control was severely criticized. The productive operation of TAXIS started in the Tax Office of Moshatou on 1998. In 2000, TAXIS covered all Greek Tax Offices.

In addition, another system was developed to enable electronic tax filling by tax payers. This was the TAXIS NET. It allows various electronic tax transactions (Hahamis et al., 2005; Terzis and Economides, 2006). Using a computer or another electronic device over public switched or dedicated telephone lines or via the Internet, tax payers could fill their tax obligations (Pant et al., 2004; Terzis and Economides, 2006).

The main purpose of this study was to investigate the use and evaluation of TAXIS by the tax office employees. The next section describes the research method that was followed.

\section{Research method}

The main objective of the questionnaire was to identify the tax employees' use of and attitude towards TAXIS, the evaluation of the TAXIS characteristics, as well as the evaluation of the new environment regarding the electronic submission of tax forms through the TAXIS NET. The responders' answers were analyzed using statistical inference techniques based on the Chi-square method. The SPSS tool was used.

Initially, a questionnaire was designed in order to capture the use of TAXIS and the employees' opinions regarding TAXIS features. After the initial design of a draft questionnaire, it was given to several employees in order to comment on it. Personal discussions with each one of them and mainly with the technical administrators contributed to the inclusion and modification of some questions.

The final questionnaire consists of three parts.

The first part investigates the employees' profiles:

- Gender (male, female)

- Age (18 - 30, 31 - 40, 41 - 50, and over 51)

- Position at work (Employee, Head of department, and Supervisor)

- Years in service (0-14, 15-24, over 25) 
- Educational level (primary education, secondary education, higher education, and postgraduate/doctorate)

The second part investigates the use of TAXIS by tax office employees. There are four close-ended questions and one open-ended question.

- How long do you use TAXIS (Never, less than 2 years, 2 until 6 years, over 6 years). Some employees do not use computers and consequently they never use TAXIS. Employees who use TAXIS less than 2 years do not know the old handwritten system in the Inland Revenue. They are also obliged to attend appropriate seminars on TAXIS. After two years of service, the employees have experience on using TAXIS. Also, employees who use TAXIS more than six years, have experience before and afterwards the TAXIS adoption.

- How often do you use the TAXIS (Not at all, 1-2 hours/day, 3-4 hours/day, 5-7 hours/day).

- Problems when using TAXIS (Yes, No, I do not know). In a positive answer, the responder could provide examples of specific problems in an open-ended question.

- Training in order to handle TAXIS (Yes, No).

The third part evaluates TAXIS:

- TAXIS evaluation with respect to ten criteria: 1) Structure \& Organization, 2) Appearance of Content, 3) Information Crosscheck, 4) Technical Support, 5) Effectiveness of Handbooks, 6) Friendly User Interface, 7) Ease of Use in Navigation and Searching, 8) Reliability, 9) Speed, and 10) Security (data Safety). The responder assigned a score from 1 (exceptionally low) to 5 (exceptionally high) to every criterion.

- Feelings caused to the responder with the introduction of TAXIS (Fear, Reserve, Indifference, Interest, and Enthusiasm).

- Improvements in the tax authorities due to TAXIS ( Not at all, little, mediocre, much, very much).

- Decrease of bureaucracy and waiting queues in the tax offices due to TAXIS NET (Yes, No or I do not know).

- In the last open-ended question, the responder could make suggestions on how TAXIS can become more effective. 
The particular evaluation criteria were chosen based on previous studies on etaxation, on the second author's extensive research and practical experience on designing and evaluating websites in several sectors, as well as on comments by the real users (tax employees) and operators of the system.

Since this was a user evaluation (and not an expert evaluation), simple criteria were chosen that make sense and could be understood by the real users (tax employees). These criteria were explicitly described to them in order to solve any misconceptions and evaluate the right parameters. Criteria that are interested to system developers (e.g. openness) were omitted. Also, criteria not appropriate for the particular case (e.g. multimedia, online payment) were omitted. For example, the users do not make any payments.

The questionnaire was given in person to 162 tax office employees in three different Greek cities (Thessaloniki, Kastoria and Argos Orestiko) during November 2007. Although there are 180 employees in these offices, 18 of them were absent and 62 of them were too busy to complete the questionnaire. The research was confronted with many difficulties, since most employees did not have free time in order to answer the questionnaire in one day. Therefore, repeated visits to these Inland Revenues offices were necessary in order to collect the employees' answers. Many employees showed interest and willingness to answer the questionnaire. They answered it voluntarily and anonymously. However, there were also employees who were bothered and tired to answer the questionnaire.

\section{Results and discussion}

After collecting the completed questionnaires, the responders' answers were input to SPSS. Then statistical analysis was performed. The responders included 62 women and $38 \mathrm{men}$. Most of them were middle-age people. Only 9 responders were under 30 years old, 28 were between 31 to 40 years old, 36 were between 41 to 50 years old, and 27 were over 51 years old. So, 63 responders were over 41 years old. It is usual that the Greek public sector does not hire young people because hiring social criteria do not favor young people.

Regarding the responders' position in service, there were 80 simple civil servants, 13 department heads, and 7 directors or sub-directors. In each one of the three Inland Revenues offices, there was one director and one sub-director. In one of these 
offices, there were two sub-directors. In an Inland Revenue office there were several departments. Usually, in a department there were up to four simple civil servants and one head. The department's head supervises and coordinates the department's employees.

Regarding their educational level, 7 responders had only primary education, 28 responders had only secondary education, 57 responders had higher education, and 8 responders had postgraduate education. So, the majority of them had at least a University degree. Regarding the years in service, 36 responders were in service less than 14 years, 31 responders between 15 to 24 years, and 33 responders over 25 years.

Regarding the years of using TAXIS, 68 responders used TAXIS for more than 6 years, while 15 responders used it for 2-4 years, 8 responders used it for less than 2 years and 9 responders did not use it at all. So, the majority of them had a great experience with TAXIS. Regarding the daily usage of TAXIS, 49 responders used it for 5-7 hours, 22 responders used it for 2-4 hours, 19 responders used it for 1-2 hours, while 10 responders did not use it. So, the majority of them used it during the whole working hours.

Regarding the awareness of problems when using TAXIS, 45 responders faced several problems, despite the fact that 61 responders were trained on TAXIS. Evaluating the TAXIS, responders were less satisfied with the Speed and the Effectiveness of Handbooks of TAXIS. On the other hand, they were very satisfied with the Security and the Reliability of TAXIS.

With the introduction of TAXIS in the tax authorities, the employees faced various feelings. Most of them felt interest (53 responders) and enthusiasm (9 responders). On the other hand, 10 responders felt fear, 9 responders felt reserve and 15 responders felt indifference. With regards to work improvement in tax authorities due to TAXIS, the majority of the responders observed much (45 responders) and very much ( 31 responders) improvement. On the other hand, only 2 responders did not notice any improvement and 2 responders observed little improvement. The rest 20 responders observed mediocre improvement.

Citizens can use TAXIS NET to declare their income via Internet instead of visiting a tax office. Half of the responders thought that TAXIS NET helped to decrease the bureaucracy. The rest 27 responders did not believe in this and 23 responders did not have an opinion. 
Next, we further analyzed their responses with respect to gender.

\section{Gender differences in the employees' responses}

We examined whether the responses of men and women differed. We performed a Chi-Square test on their answers. If the calculated P-value is less than 0.05, there is a statistically significant relationship between the two classifications. Moreover, the Contingency Coefficient (CC) is a measure of the degree of relationship. The larger the value of this coefficient is, the greater the degree of association. In most cases, there were not significant differences. Gender differences were located in their TAXIS daily usage, problems awareness, feelings and considerations about its Security (Table 1).

[Insert Table 1]

Most men (45\%) were 41-50 years old, while most women were almost equally allocated in the ranges of 31-40 years old (32\%) and 41-50 years old (31\%).

The majority of both men (79\%) and women (81\%) were simple employees. More women were department heads (15\%) than men (11\%). On the contrary, more men were directors or sub-directors (11\%) than women (5\%).

Regarding the years in service, women were evenly allocated in the three periods (one third in each period). However, there were more men with $0-14$ years in service (40\%) than in the other two periods.

Regarding the educational level, the majority of both men (71\%) and women (48\%) had higher education. Less than $8 \%$ of both genders had only primary education. However, there were enough women (37\%) holding only a secondary education degree.

Regarding the years of using TAXIS, most women (69\%) and men (66\%) used TAXIS for more than 6 years. However, more men (16\%) than women (5\%) did not use TAXIS at all because they had other duties (e.g. outdoors controllers, office boys and cashiers).

\subsection{Gender differences in TAXIS usage}

Next, we investigate how much time per day they use TAXIS. This time depends mainly on their duties. Almost all responders need to communicate with taxpayers from 8:00 to 14:30. Then they work on their other duties until 15:00. The majority of 
both men (37\%) and women (56\%) used TAXIS for 5-7 hours per day. The rest men were levelly distributed: 3-4 hours/day (21\%), 1-2 hours/day (21\%), and not at all (21\%). On the other hand, only 3\% women did not use TAXIS at all. In general, most women used TAXIS many hours/day because they had dealings mainly with tax payers. Consequently, there are significant differences among female and male responders regarding the daily usage of TAXIS.

While working on TAXIS, almost half of men (41\%) and women (47\%) were confronted with various problems regarding TAXIS. Furthermore, some men (35\%) were not sure about the existence of any problems. Finally, some men (24\%) and women (40\%) did not face any problems. It is possible that more women than men were confronted with TAXIS problems because they used it more hours/day than men did. The statistical analysis revealed that a significant dependence exists between gender and awareness of TAXIS problems.

Employees should be trained in order to effectively perform their duties. Knowledge could enable employees to face cases and problems successfully. So, the tax authorities should provide training to all tax office employees on using TAXIS. However, training on TAXIS was voluntarily. Although government motivated the tax employees to be trained, it could not force them to successfully complete a training seminar. So, an important factor was the employees' willingness for training and learning. Only 61 responders had received any training on using TAXIS. Remarkably, only half of men had been trained on TAXIS. Double women had received training on TAXIS (68\%) than those who have not (32\%).

With the introduction of TAXIS in the tax authorities, tax officials were confronted with new ways of working and new technologies. This change caused to them various feelings. With an amazing majority, most men (42\%) and women (60\%) felt interest regarding this new environment. More men (24\%) than women (6\%) felt enthusiasm. Also, more men (16\%) than women (6\%) felt fear. However, more women (13\%) than men (3\%) felt reservation. Statistical analysis showed that there was a dependency between employees' sentiments and gender-related distribution.

Regarding the improvement of work in tax authorities due to TAXIS, most men equally gave grade $=4(37 \%)$ and grade $=5(37 \%)$. Half of women gave the grade $=4$. Finally, the majority of both men (45\%) and women (53\%) agreed that TAXIS helped to fight the tax office bureaucracy. 


\subsection{Gender differences in evaluating TAXIS characteristics}

In the sequence, the employees evaluated the TAXIS characteristics. Ten responders did not evaluate the TAXIS characteristics, because they did not use it. The rest graded each one of the following characteristics: Structure \& Organization, Appearance of Content, Information Crosscheck, Technical Support, Effectiveness of Handbooks, Friendly User Interface, Ease of Use, Reliability, Speed, and Security. They assigned a grade from 1 (exceptional low) to 5 (exceptionally high) to each characteristic.

The responders were satisfied with the TAXIS Structure and Organization (Figure 1). However, women gave higher grades (grade $=3$ by $39 \%$ and grade $=4$ by $32 \%$ ) than men $\operatorname{did}$ (grade $=3$ by $24 \%$ and grade $=4$ by $26 \%$ ).

[Insert Figure 1]

The responders were satisfied with the TAXIS Appearance of Content (Figure 2). However, women gave higher grades (grade $=3$ by $36 \%$, and grade $=4$ by $34 \%$ ) than men $\operatorname{did}$ (grade $=3$ by $32 \%$ and grade $=4$ by $21 \%$ ).

[Insert Figure 2]

The responders were satisfied with the TAXIS Information Crosscheck (Figure 3). However, women gave higher grades (grade $=3$ by $34 \%$ and grade $=4$ by $32 \%$ ) than men $\operatorname{did}$ (grade $=3$ by $26 \%$ and grade $=4$ by $21 \%$ ).

[Insert Figure 3]

The responders were satisfied with the TAXIS Technical Support (Figure 4). The majority of women $(42 \%)$ gave grade $=4$, while the majority of men $(34 \%)$ gave grade $=3$.

[Insert Figure 4]

The responders were not quite satisfied with the TAXIS Handbooks (Figure 5). The majority of men gave grade $=3$ (29\%). Women almost uniformly gave grades 2 (24\%), 3 (24\%) and 4 (26\%). However, some men (18\%) and women (13\%) gave grade $=1$.

[Insert Figure 5]

The responders were satisfied with the TAXIS User Interface (Figure 6). However, women gave higher grades (grade $=3$ by $29 \%$ and grade $=4$ by $34 \%$ ) than men did (grade $=3$ by $24 \%$ and grade $=4$ by $24 \%$ ).

[Insert Figure 6] 
The responders were satisfied with the TAXIS Ease of Use (Figure 7). The majority of women $(37 \%$ _ gave grade $=4$, while the majority of men (37\%) gave grade $=3$.

[Insert Figure 7]

The responders were very satisfied with the TAXIS Reliability (Figure 8). The majority of women (44\%) and men (34\%) gave grade $=4$.

[Insert Figure 8]

The responders were less satisfied with the TAXIS Speed (Figure 9). The majority of women $(40 \%)$ gave grade $=3$, while the majority of men $(32 \%)$ gave grade $=2$.

[Insert Figure 9]

Finally, the responders were satisfied with the TAXIS Security (data Safety) (Figure 10). The majority of both women (42\%) and men (53\%) gave grade=4. Statistical analysis showed that a difference exists between employees' opinions about TAXIS Security and gender-related distribution.

[Insert Figure 10]

On average, responders were very satisfied with TAXIS Security (data Safety), and dissatisfied with the TAXIS Effectiveness of Handbooks (Table 2, Graph).

[Insert Table 2] 


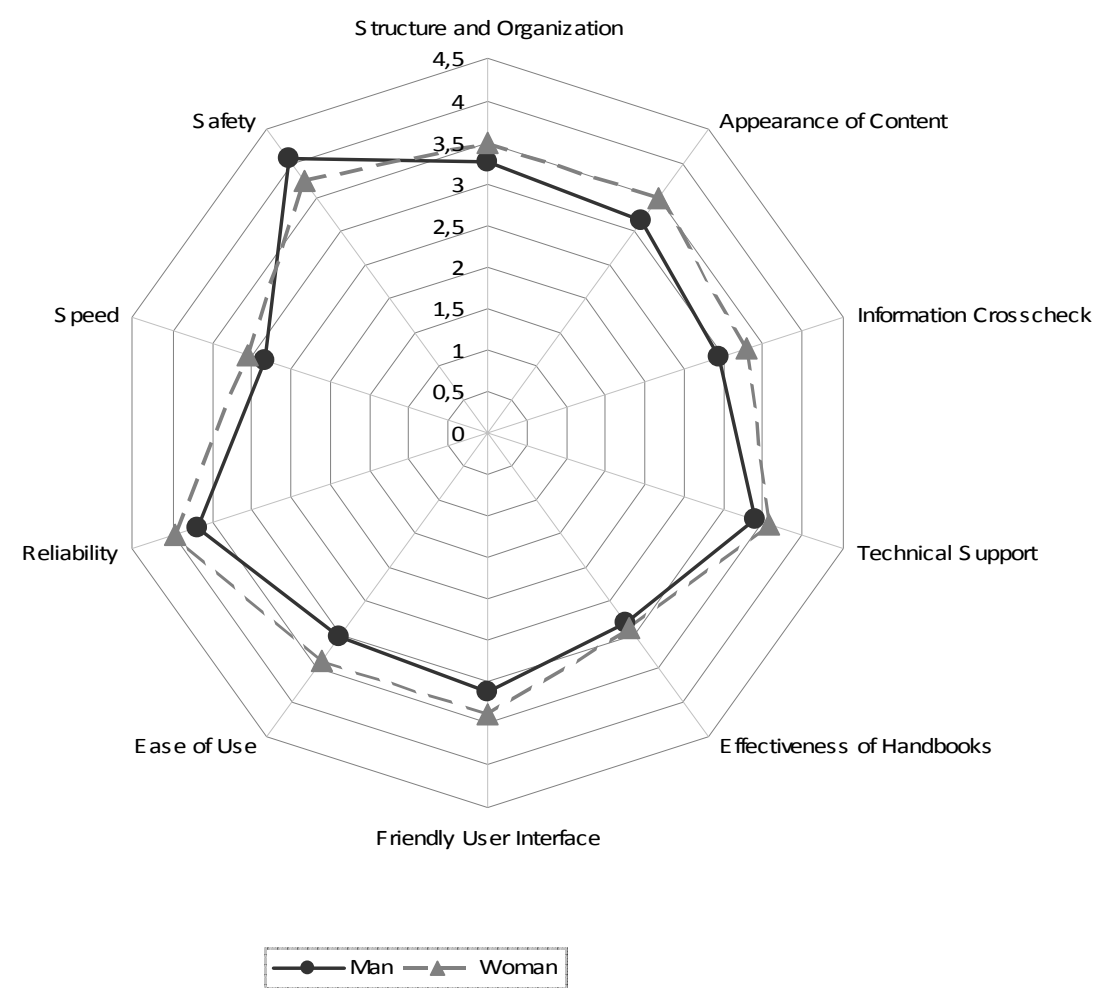

\section{Graph: TAXIS characteristics “Average Grades”}

Men gave an "Average Grade" > 4 to TAXIS Security. However, they gave an "average grade" $<3$ to TAXIS Information Crosscheck, Effectiveness of Handbooks and Speed. On the other hand, women gave higher grades than men to all TAXIS characteristics except Security. Most women have been trained and used TAXIS more hours/day than men did. Also, they were more aware about the TAXIS problems than men. One could think that either they had more knowledge than men about TAXIS security problems or they did not trust too much the technology. They were also dissatisfied with the TAXIS Handbooks.

\section{Open-ended questions results}

This section reports the results of the responses to the open-ended questions. The responders mentioned several problems that they encountered during the use of TAXIS. They also proposed improvements to be made.

Almost half of the responders reported problems while using TAXIS. In summary, the following problems were spotted:

1. Inability to search information about a company using its name. 
2. Low speed of processing data. This has also an effect on printing (e.g. printing ten pages required 45 minutes).

3. Inability to download and print data based on multiple criteria.

4. Inability to use two TAXIS applications simultaneously.

5. The central system of TAXIS was overloaded very often. As a result, the connection

to the central system was interrupted temporarily and the tax payers' service was delayed.

6. A server's damage could cause problems in using the client-computers.

7. Electricity interruptions caused the use of TAXIS impossible.

8. The speed of downloading data is not very high.

9. Many necessary tax objects (elements) were not supported by (included in) TAXIS. For example, the field "Capital" was not included.

10. There was not connection among various menus of TAXIS. Changing the screen from one menu to another caused large delays.

11. There was not immediate update of information. Changes in the elements of a tax payer by a department (e.g. Income) did not become known automatically to other departments (e.g. Registration). Consequently, the local system of tax authorities was informed insufficiently.

12. The local area network often crashes.

Next, the responders suggested ways to make TAXIS more effective. After assembling their answers, it was realised that the responders agreed on specific ways to improve TAXIS. Basically, they suggested fixing the TAXIS problems. The continuous technology advances pushes the users' expectations and training needs high. In order to enhance the TAXIS operation, a team could continuously monitor and record the TAXIS problems, weaknesses and inefficiencies. Then, the necessary upgrades could be scheduled and implemented.

Several functional and operational problems should be resolved. For instance, when a partner of a consortium has to pay debts to the State, the consortium is blocked and can not certify its accounting books and elements. This should be bypassed and allow the consortium to proceed. It is also essential to enable communication and interoperability of TAXIS with other applications. It is urgent to interconnect all the departments of Inland Revenue as well other financial services. The online connection with services of Ministry of Finance should ensure right and 
complete crosscheck of information. It is also important to connect TAXIS to other public institutions such as Police Stations, Courts, Insurance Funds and Banks. Integrating all related services in TAXIS could decrease the existing bureaucracy and could provide better services to the tax payers. Citizens should not be obliged to collect various documents from various public departments in order to complete a transaction with the State.

The responders regarded necessary the development of an integrated information system that will include the activities of all the departments of an Inland Revenue enabling online communication among them. They pointed out that a tax office employee should be able to see the complete picture of a taxpayer. Specially, the auditors considered essential the access to as many as possible information about professional tax payers or businesses.

While TAXIS is used by tax office employees, another major information system is TAXIS NET which is mainly used by tax payers to declare their income. Currently, not many tax payers use TAXIS NET. The responders proposed that motives should be given to tax payers in order to use TAXIS NET. Furthermore, a specialized workstation should be developed so that tax payers could interact with Inland Revenue via this workstation. Such workstations should be placed inside the tax offices where the tax payers could send and receive tax related forms or even pay tax obligations. Also, tax employees should help the tax payers in using these workstations. In order to increase the users' positive attitude towards e-Government services, governmental agencies should develop implementation strategies that emphasize the usefulness of TAXIS NET services, the users' trust and work style compatibility. Moreover, several new services should be included in TAXIS NET. For example, the submission of "Balances" to the department of "Books and Elements Code" forces citizens to arrive at tax offices and create queues. So, TAXIS NET should include this service. In addition, simplifying the TAXIS NET menu, and advertising any new user friendly changes could enable inexperienced users to use it.

E-government requires new ways of work and handling of public affairs by public servants. They need to improve their skills and knowledge on adopting, using and exploiting new technology. It is necessary that they continuously be trained on these new developments. 


\section{Conclusions and future research}

An empirical study was conducted to identify tax employees' usage and opinions about TAXIS, a major Greek government information system. A sample group of 100 tax employees answered a questionnaire. Regarding the TAXIS incorporation into their work, most of them felt interest and noticed both decrease of bureaucracy and improvement of work. Most of them used TAXIS for more than 6 years, at least 5-7 hours daily, and they had attended relevant seminars. They encountered various problems while using TAXIS. The most frequent problem was the weakness of using two applications simultaneously. Most of them were satisfied with TAXIS characteristics except of the system's handbooks and the system's speed. Finally, the responders called for a more effective tax information system that will interconnect all related government institutions.

Gender differences were identified in the following areas: Daily usage of TAXIS; Awareness of TAXIS problems; Evaluation of the TAXIS Security; Observation of improvement in tax authorities with the TAXIS introduction.

As it is usual in surveys, the limitations of this study are related to the sample. The sample was not random and representative. The participants were restricted to 3 Greek cities and they evaluated a specific information system (TAXIS). This limits the generalization of the findings to other populations and information systems. Also, the investigation was restricted to public employees in the Greek Inland Revenue Services. It could be extended to include employees in other public and/or private organizations as well in other countries. Another limitation is related to the temporality of any study regarding technology and people. Both technology and people change. So, after some time a more advanced information system than the current TAXIS could be in operation, and more educated employees could be employed. Finally, some employees were not willing to answer the questionnaire and therefore the findings do not include their perspective.

Future research should investigate the usage and evaluate the characteristics of other public information systems either in Greece or in other countries by either public servants or citizens depending on its scope.

\section{References}


Altameem, T., Zair, M., \& Alshawi, S. (2006). Critical success factors of egovernment: A proposed model for e-government implementation. Proceedings Conference on Innovations in Information Technology, IEEE, 1-5.

Avgerou, C. (2002). Information systems and global diversity. Oxford University Press, New York.

Beattie, V., \& Pratt, K. (2003). Issues concerning web-based business reporting: An analysis of the views of interested parties. The British Accounting Review, 35(2), $155-187$.

Bray, R. (2003). The online taxman: Championing change leads to success at CCRA. Canada's Magazine on public sector purchasing, Retrieved on January 12, 2008 from http://www.allbusiness.com/legal

Bronchi, C. (2001). Options for reforming the tax system in Greece. OECD Economics Department Working Papers, No. 291, OECD Publishing, 1-74.

Carter, L., \& Bélanger, F. (2005). The utilization of e-government services: citizen trust, innovation and acceptance factors. Information System J ournal, 15(1), 5-25.

Economides, A. A., \& Terzis, V. (2008). Evaluating tax sites: an evaluation framework and its application. Electronic Government, an International J ournal 5(3), 321-344.

Gouscos, D., Mentzas, G., \& Georgiadis, P. (2001). Planning and implementing egovernment service delivery: Achievements and learnings from on-line taxation in Greece. Workshop on e-Government in the context of the 8th Panhellenic Conference on Informatics, Nicosia, Cyprus, 1-8.

Gouscos, D., Georgiadis, P., \& Sagris, T. (2000). From introvert IT systems to extrovert e-services: Government as an enabler for e-citizens and e-business- A framework of principles. Electronic Business and Electronic Work Conference, 1-7. 
Hahamis, P., Iles, J., \& Healy, M. (2005). E-government in Greece: Bridging the gap between need and reality. Electronic J ournal of e-Government, 3 (4), 185-192.

Hirschheim, R., \& Smithson, S. (1999). Evaluation of information systems: A critical assessment. In Willcocks L. and Lester S. (Eds.), Beyond the IT Productivity Paradox West Sussex, UK, J. Wiley \& Sons, 381-409.

Irani, Z. (2002). Critical evaluation and integration of information systems. Business Process Management J ournal, 8(4), 314-317.

Irani, Z., \& Love, P. E. D. (2001). The propagation of technology management taxonomies for evaluating investments in information systems. Journal of Management Information Systems, 17(3), 161-177.

Jones, S., Irani, Z., \& Sharif, A. (2007). E-government evaluation: Reflections on three organisational case studies. Proceedings of the 40th Hawaii International Conference on System Sciences, IEEE, 1-8.

Khoja, M. A. (2004). E-government: From theory to application. IEEE Proceedings International Conference on Information and Communication Technologies: From Theory to Applications, 17-18.

Lau, C., \& Halkyard, A. (2003). From e-commerce to e-business taxation. AsiaPacific Tax Bulletin, Prentice Hall PTR Upper Saddle River, 1-12.

Malazdrewicz, M. (1992). En route to online filing. CA Magazine, 125 (10), 44-46.

Moon, J. M., \& Welch, E. W. (2005). Same bed, different dreams? A comparative analysis of citizen and bureaucrat perspectives on e-government. Review of Public Personnel Administration, 25 (3), 243-264.

Norris, P. (2001). Digital divide. Cambridge, Cambridge University Press. 
Pant, V., Stiner, M. S., \& Wagner, P. W. (2004). E- Taxation: An introduction to the use of TaxXML for corporate tax reporting. Journal of Electronic Commerce in Organizations, 2(1), 29-41.

Remenyi, D., Money, A., Sherwood, S., \& Irani, Z. (2000). Effective measurement and management of IT costs and benefits. Butterworth-Heinemann, Oxford.

Rocheleau, B., \& Wu, L. (2005). E-Government and financial transactions: Potential versus reality. Electronic Journal of e-Government, 3(4), 219-230. Available at: www.ejeg.com

Sharma, A., \& Yurcik, W. (2004). An e-tax internet filing system incorporating security and usability best practises. International Conference on E-Business and Telecommunication Networks (ICETE), 1-7. Retrieved on December 20, 2006 from: http://www.ncsa.uiuc.edu/ aashish/papers/Sharma_Yurcik_ICETE2004.pdf

Stamoulis, D. S., Gouscos, D., Georgiadis, P., \& Martakos, D. (2001). Re-orienting imformation systems for customer-centric service: The case of the Greek Ministry of finance. Proceedings 9th European Conference on Information Systems, 977-986.

Taylor, S. A. (2003). American tax systems as examples of successful e-government. Proceedings 18th BILETA, Conference: Controlling Information in the online Environment, 1-7.

Terzis, V., \& Economides, A. A. (2006). Internet-based tax filling. Proceedings First International Conference in Accounting and Finance, ICAF.

Terzis, V., \& Economides, A. A. (2007). Critical success factors for tax web sites. In: E-Taxation: State \& Perspectives: E-Government in the field of Taxation, J. Makolm \& G. Orthofer (eds.), Trauner Verlag in its Informatics Series, 56-67.

Tsiavos, P., Smithson, S., \& Kotyvos, S. (2002). A path of discontinuity: The TAXIS case as a transition from e-government to e-regulation. In T. J. M. Bench-Capon, A. 
Daskalopulu, \& R. G. F. Winkels (eds.), Legal knowledge and information systems, Amsterdam, IOS Press, 53-62.

Walsh, S. T., \& White, C. G. (2000). Congress's goal of increasing electronic filing: An assessment based on the technology-adoption literature. American Accounting Horizons, 14(4), 403-425.

Wang, L., Bretschneider, S., \& Gant, L. (2005). Evaluating web-based e-government services with a citizen-centric approach. Proceedings of the $38^{\text {th }}$ Hawaii International Conference on System Sciences, IEEE, 129b-129b.

Wang, Y. (2003). The adoption of electronic tax filing systems: an empirical study. Government Information Quarterly, 20(4), 333-352.

Willcocks, L., \& Lester, S. (1999). Information technology: Transformer or sink hole. Beyond the IT productivity paradox, Willcocks, L. and Lester, S. (eds.), West Sussex, UK, J. Wiley \& Sons, 1-36. 


$$
\begin{array}{llll}
\mathrm{X}^{2} & \mathrm{DF} & \mathrm{P} & \mathrm{CC}
\end{array}
$$

$\begin{array}{lllll}\text { Age } & 3.393 & 3 & 0.335 & 0.181 \\ \text { Position at work } & 1.386 & 2 & 0.5 & 0.117 \\ \text { Years of work } & 0.666 & 2 & 0.717 & 0.081 \\ \text { Educational level } & 7.016, & 3 & 0.071 & 0.256 \\ \text { Years of using TAXIS } & 5.417 & 3 & 0.144 & 0.227 \\ \text { Daily use of TAXIS } & 9.497 & 3 & \mathbf{0 . 0 2 3} & 0.295 \\ \text { Problems with TAXIS } & 7.329 & 2 & \mathbf{0 . 0 2 6} & 0.263 \\ \text { Training on TAXIS } & 3.117 & 1 & 0.077 & 0.174\end{array}$

$\begin{array}{lccll}\text { TAXIS Organization } & 9.976 & 5 & 0.076 & 0.301 \\ \text { TAXIS Content Appearance } 8.434 & 5 & 0.134 & 0.279 \\ \text { TAXIS Info Crosscheck } & 6.246 & 5 & 0.283 & 0.242 \\ \text { TAXIS Technical Support } & 8.990 & 5 & 0.109 & 0.287 \\ \text { TAXIS Handbook } & 8.99 & 5 & 0.109 & 0.287 \\ \text { TAXIS User Interface } & 7.335 & 5 & 0.197 & 0.261 \\ \text { TAXIS Ease of Use } & 9.292 & 5 & 0.098 & 0.292 \\ \text { TAXIS Reliability } & 10.257 & 5 & 0.068 & 0.305 \\ \text { TAXIS Speed, } & 7.984 & 5 & 0.157 & 0.272 \\ \text { TAXIS Security } & 10.768 & 4 & \mathbf{0 . 0 2 9} & 0.312\end{array}$

$\begin{array}{lcccc}\text { Feelings } & 11.596 & 4 & \mathbf{0 . 0 2 1} & 0.322 \\ \text { Improvements } & 1.860 & 4 & 0.762 & 0.135 \\ \text { Bureaucracy decrease } & 4.491 & 2 & 0.106 & 0.207\end{array}$

Table 1. Gender differences 


\begin{tabular}{lccc} 
& Man & Woman & Overall \\
\cline { 2 - 4 } Structure and Organization & 3,25 & 3,49 & 3,4 \\
Appearance of Content & 3,16 & 3,49 & 3,37 \\
Information Crosscheck & $\mathbf{2 , 9 3}$ & 3,28 & 3,23 \\
Technical Support & 3,38 & 3,55 & 3,5 \\
Effectiveness of Handbooks & $\mathbf{2 , 8 3}$ & $\mathbf{2 , 9 1}$ & $\mathbf{2 , 8 8}$ \\
Friendly User Interface & 3,12 & 3,37 & 3,38 \\
Ease of Use & 3,03 & 3,38 & 3,26 \\
Reliability & 3,67 & 3,93 & $\mathbf{3 , 8 4}$ \\
Speed & $\mathbf{2 , 8 3}$ & 3,03 & $\mathbf{2 , 9 6}$ \\
Security & $\mathbf{4 , 0 6}$ & 3,76 & $\mathbf{3 , 8 6}$
\end{tabular}

Table 2: “Average Grades” of TAXIS characteristics 


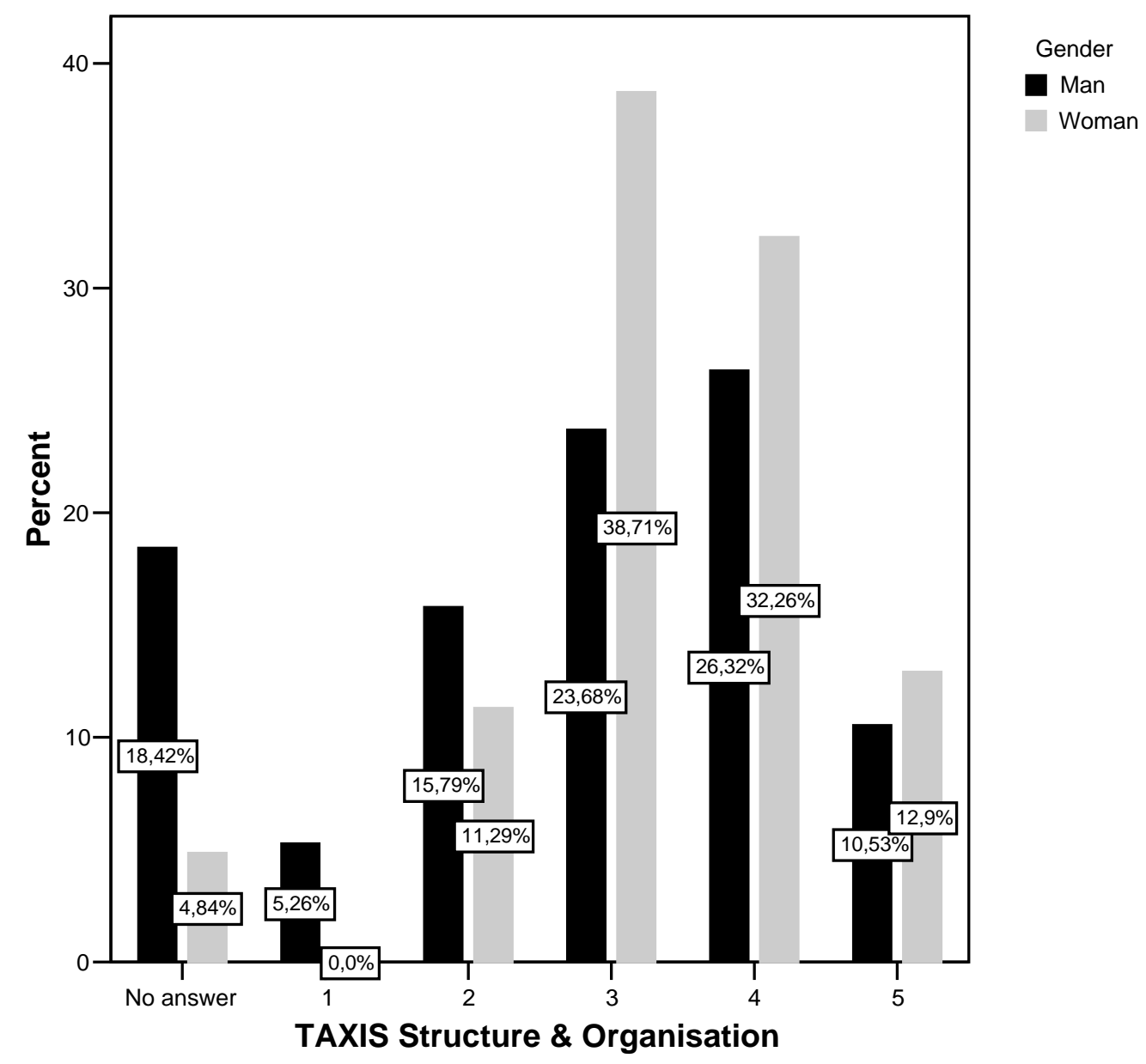

Figure 1: Evaluation of the TAXIS Structure and Organization 


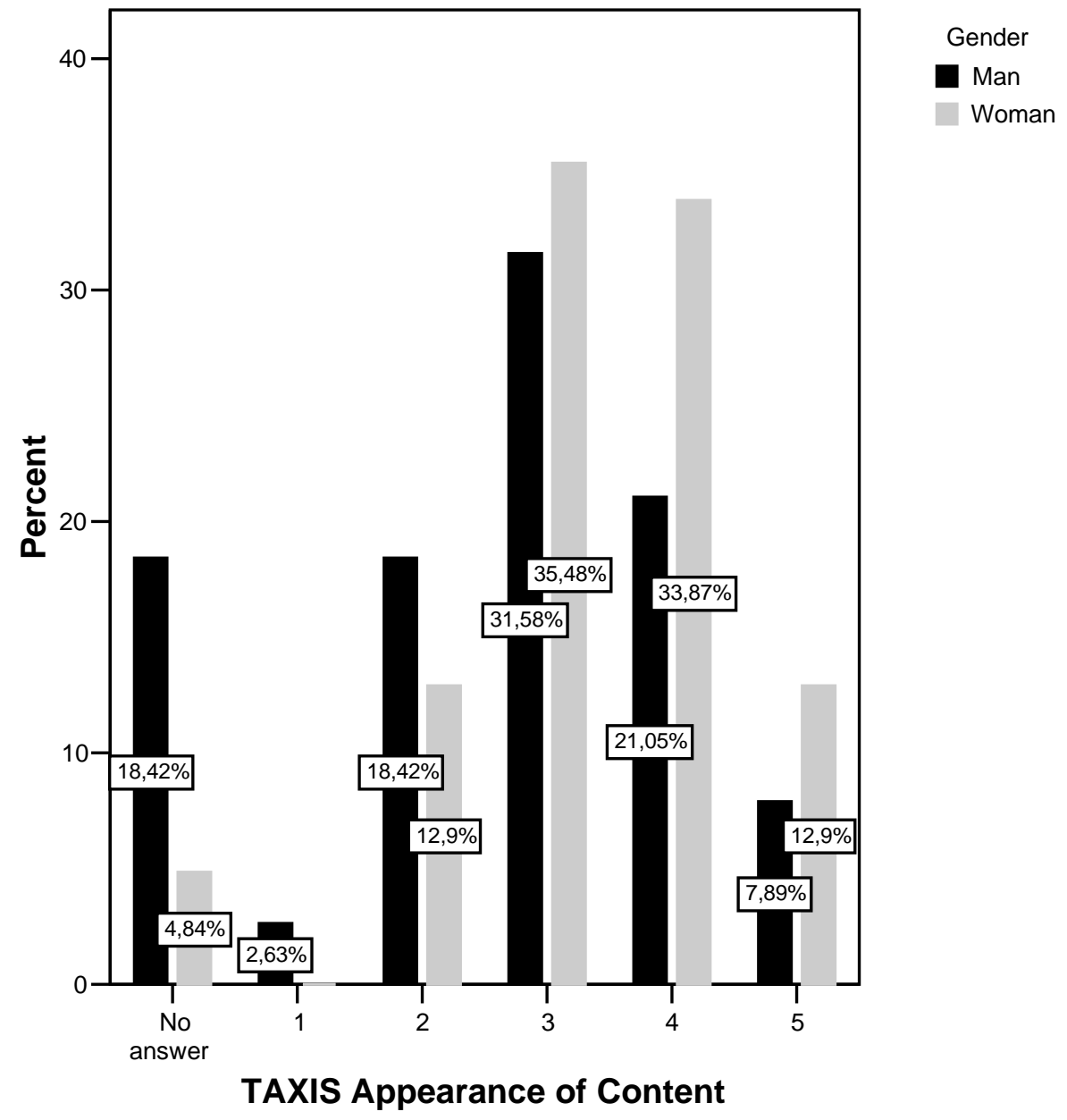

Figure 2: Evaluation of the TAXIS Appearance of Content by men and women 


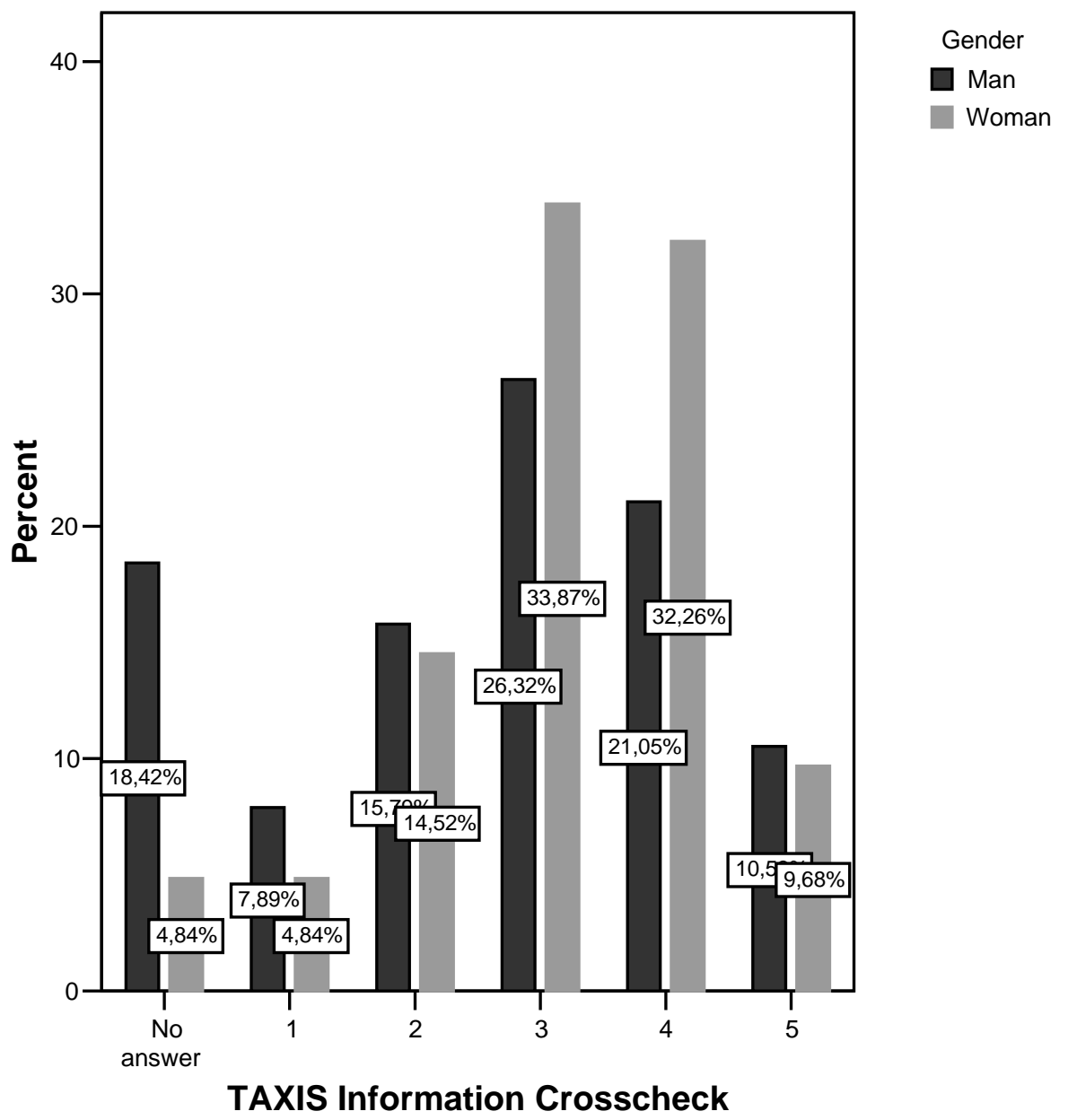

Figure 3: Evaluation of the TAXIS Information Crosscheck by men and women 


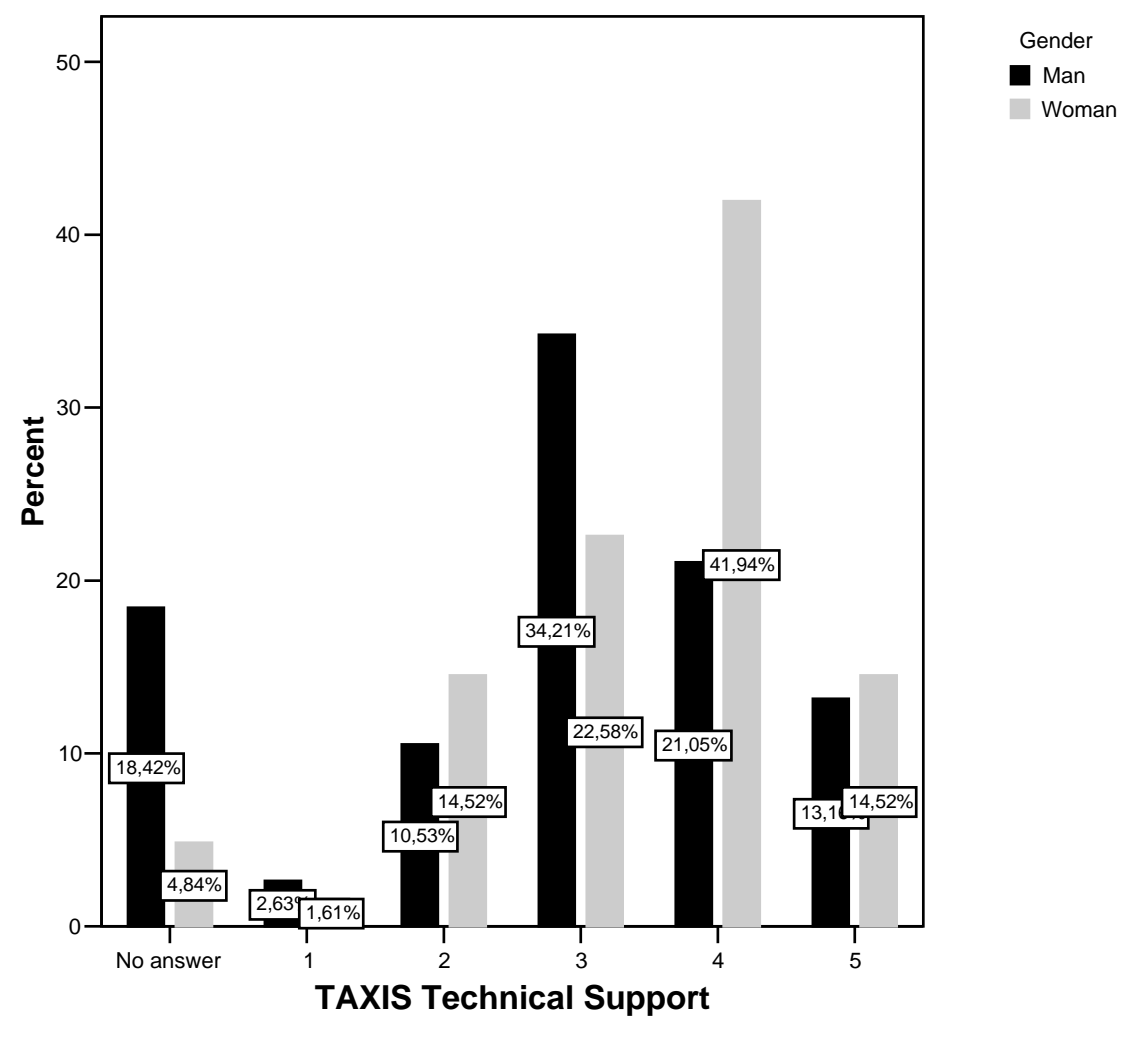

Figure4: Evaluation of the TAXIS Technical Support by men and women 


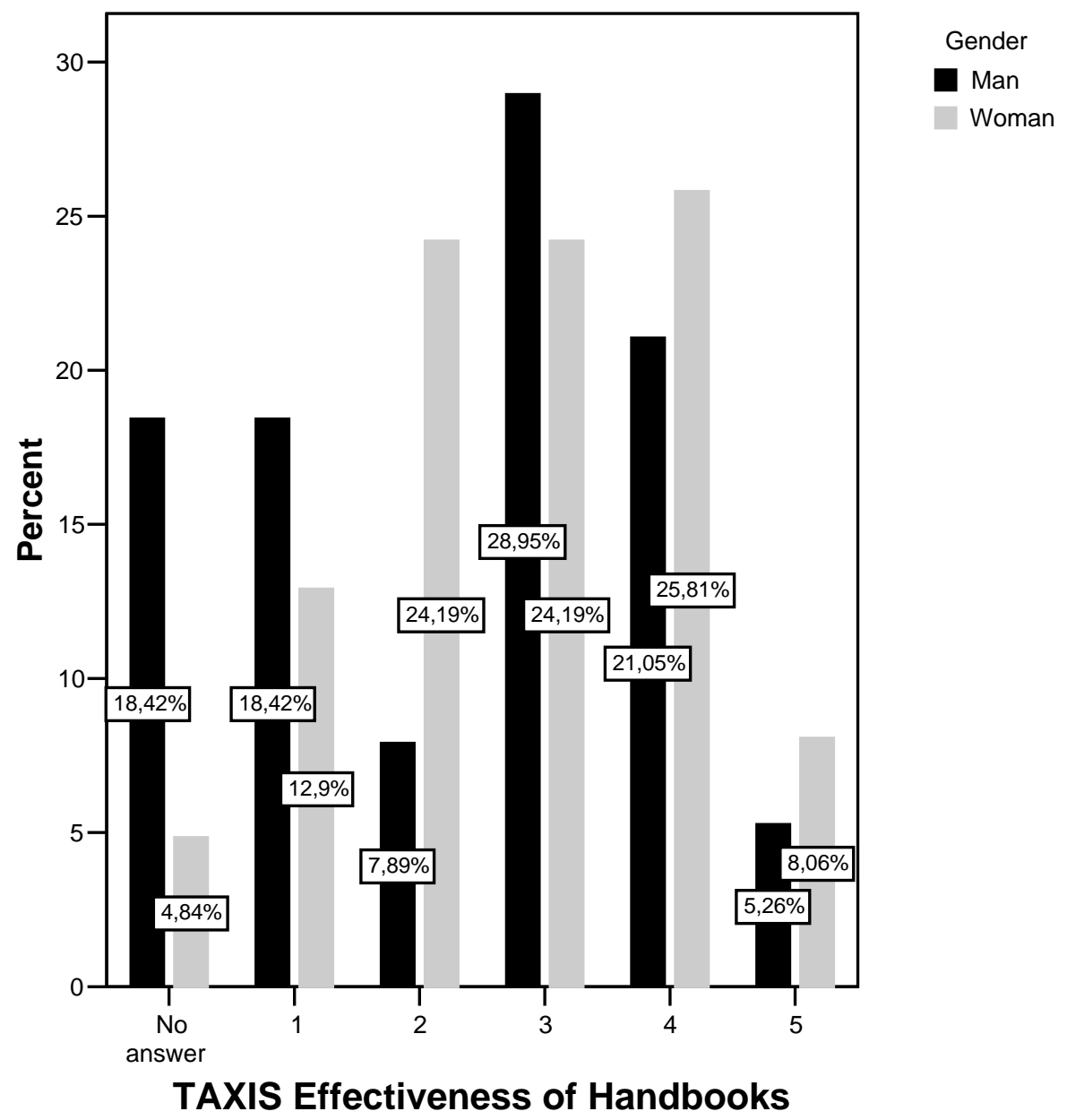

Figure 5: Evaluation of the TAXIS Effectiveness of Handbooks by men and women 


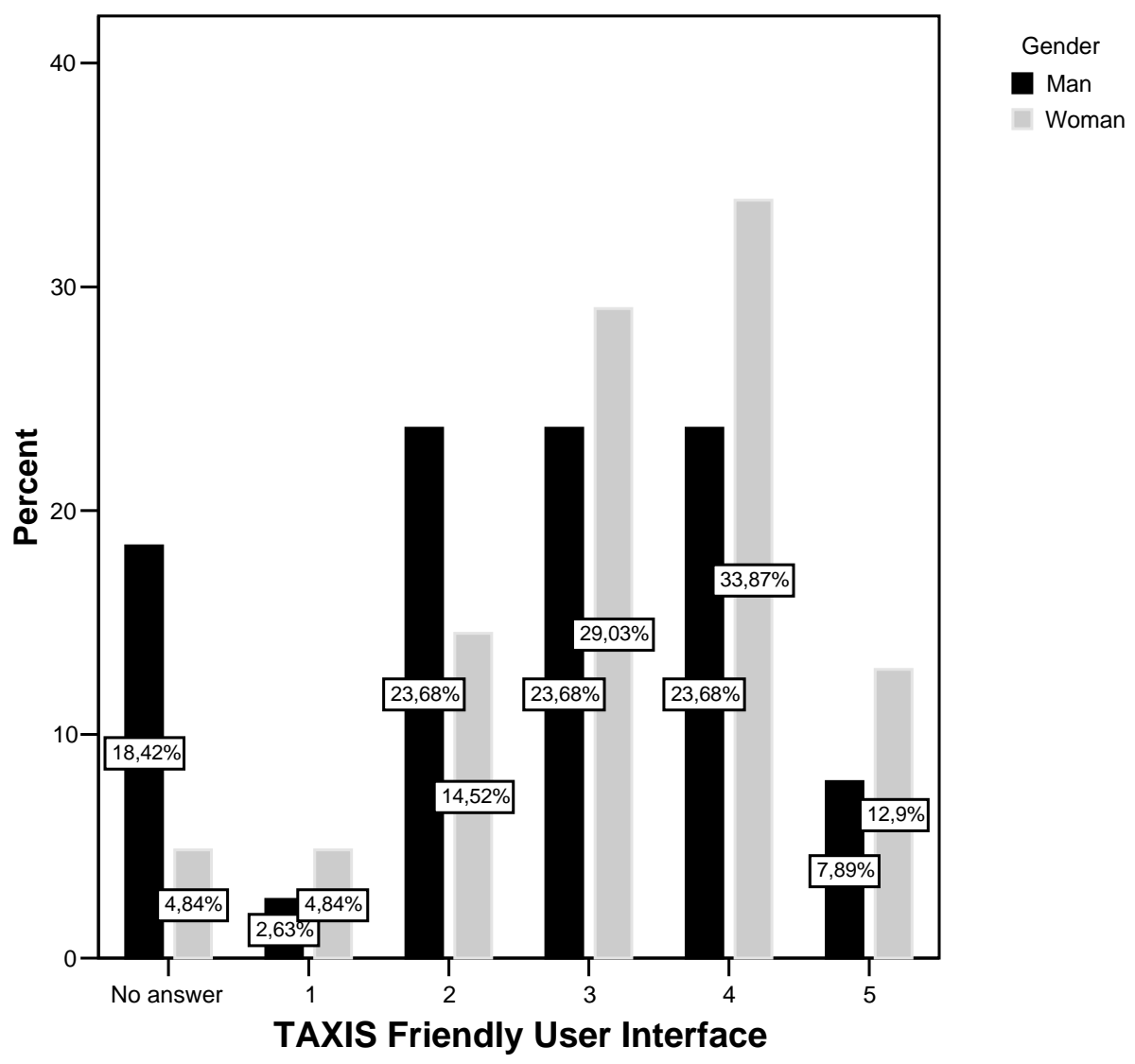

Figure 6: Evaluation of the TAXIS Friendly User Interface by men and women 


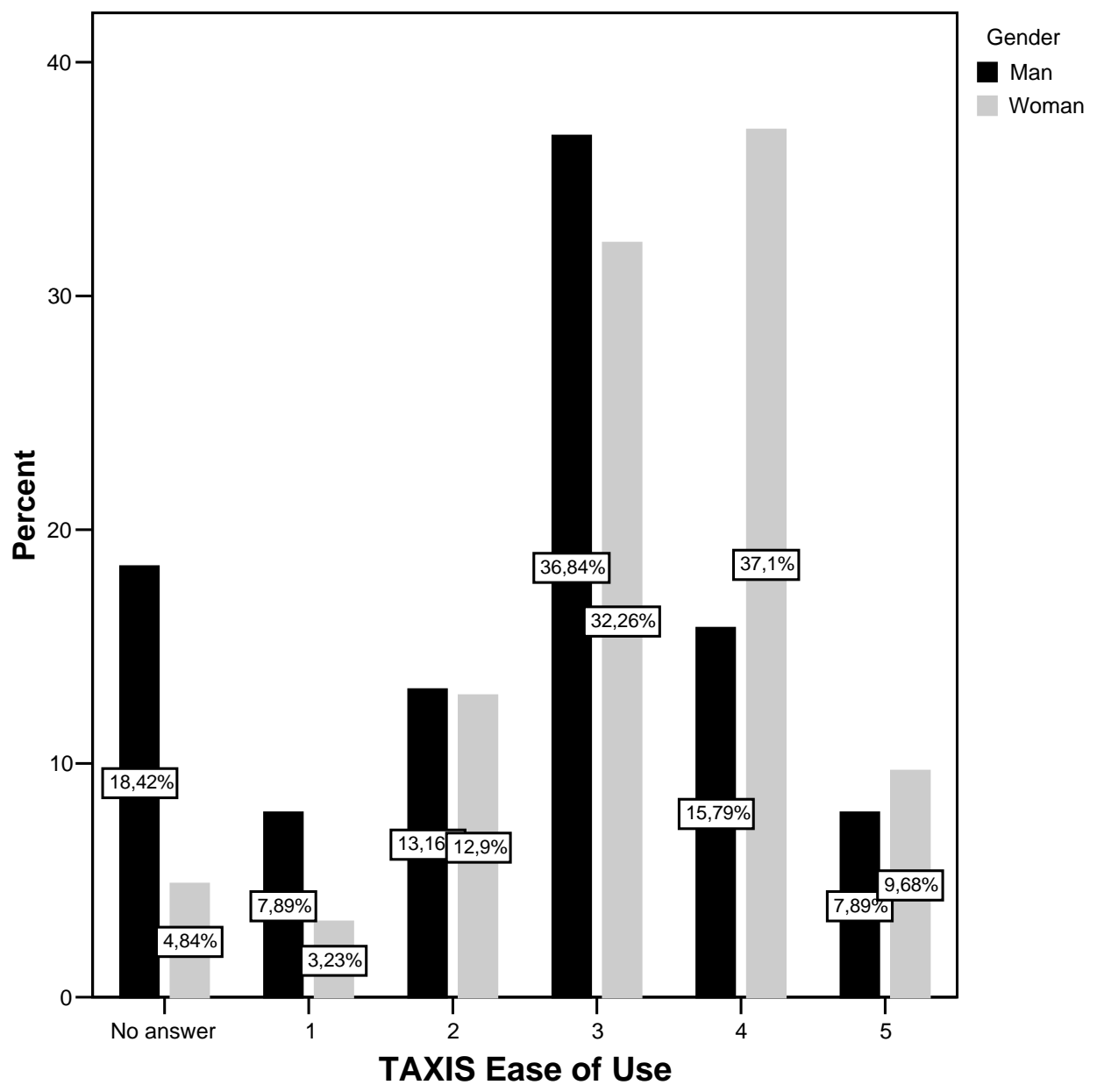

Figure 7: Evaluation of the TAXIS Ease of Use by men and women 


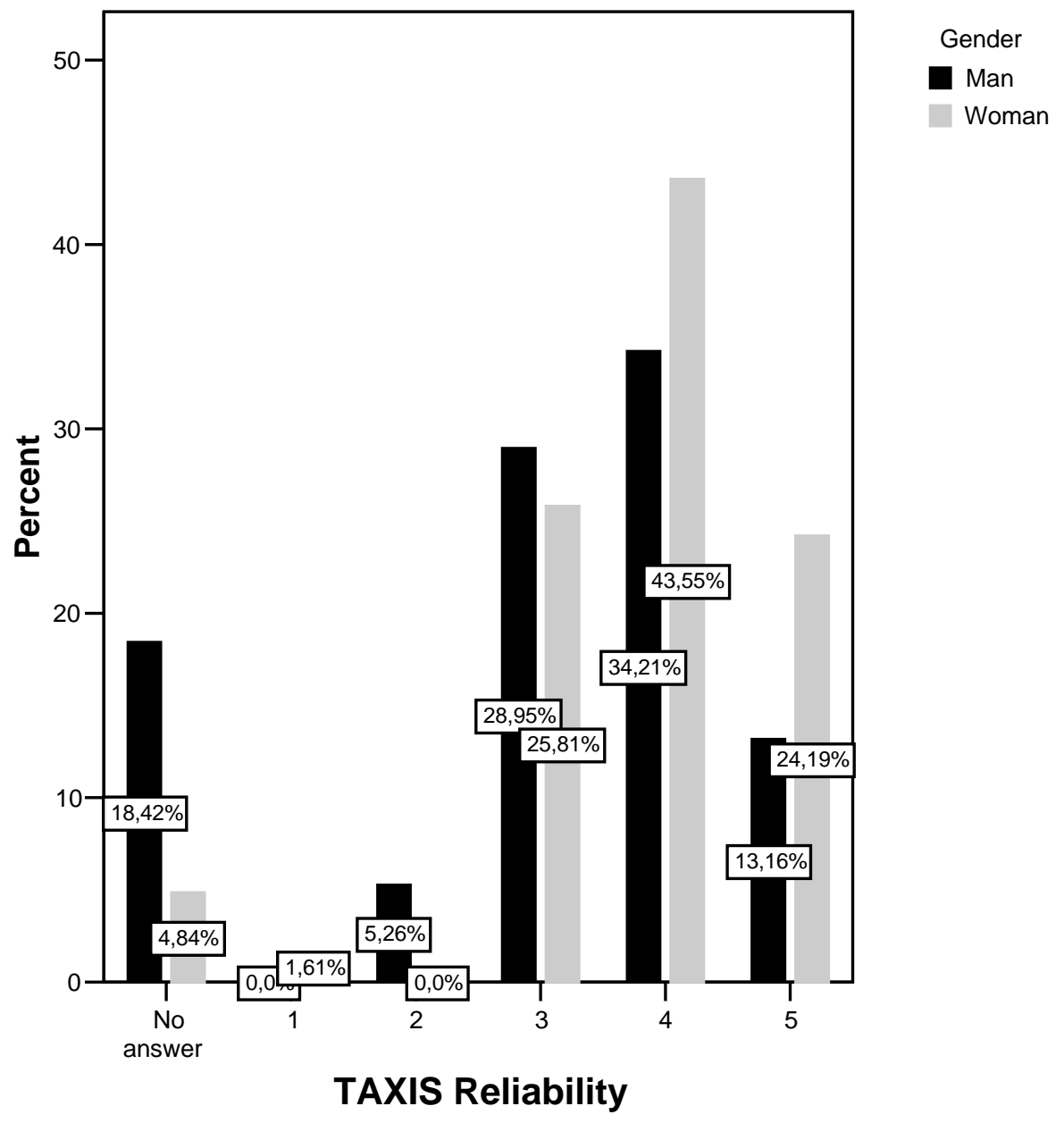

Figure 8: Evaluation of the TAXIS Reliability by men and women 


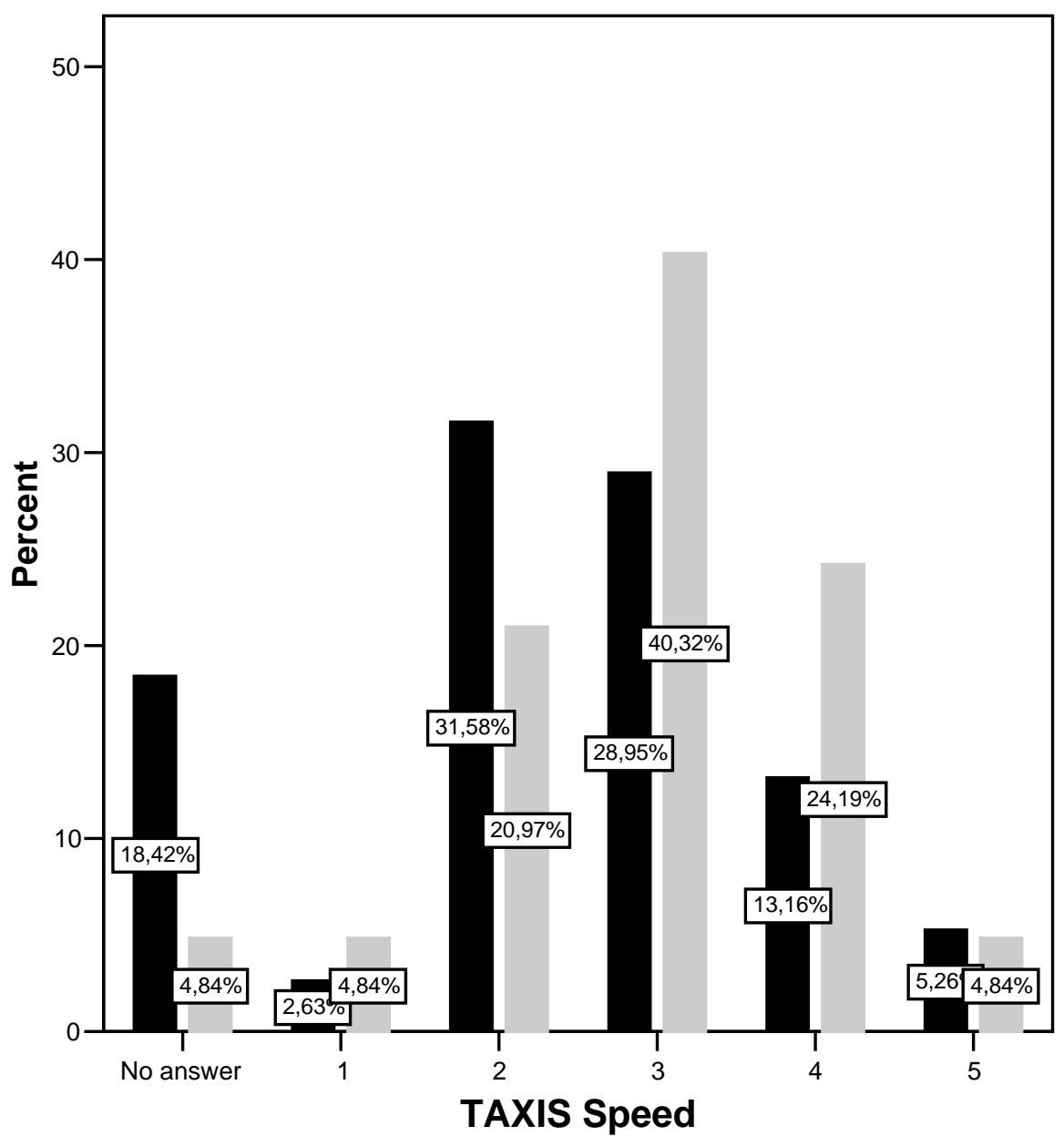

Gender

Man

Woman

Figure 9: Evaluation of the TAXIS Speed by men and women 


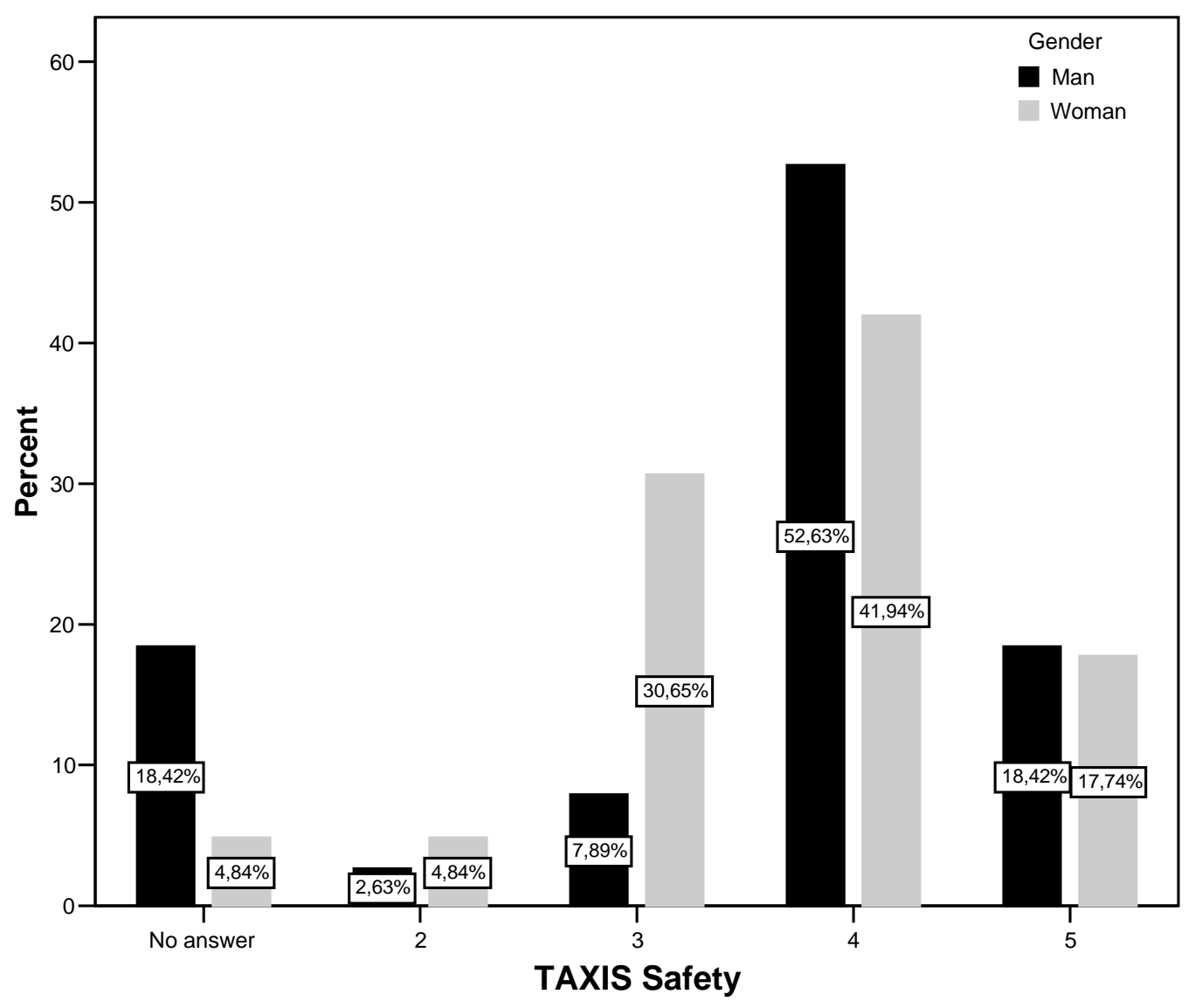

Figure 10: Evaluation of the TAXIS Security (data Safety) by men and women 